\title{
Sentidos e sujeitos \\ em cena na notícia em TV: \\ A incorporação da análise do discurso \\ nos estudos de telejornalismo
}

\author{
Iluska Maria da Silva Coutinho* \\ Jhonatan Alves Pereira Mata**
}

Artigo recebido em:

11 de setembro de 2009

Aprovado em:

30 de março de 2010

* Jornalista, mestre em Comunicação

e Cultura (UnB) e doutora em

Comunicação Social

(Unesp). Professora do departamento de Jornalismo e do PPGCOM da UFJF, coordena o

GP Telejornalismo da Intercom, e integra a Rede de Pesquisadores de Telejornalismo

(SBPJor).

iluskac@uol.com.br

** Mestrando do

Programa de Pós

Graduação em

Comunicação

da UFJF, linha

"Comunicação

e Identidades".

Jornalista graduado, integrante do grupo de pesquisa

Comunicação, Identidade e

Cidadania (CNPq).
Resumo: Os sentidos - e os efeitos que estes produzem nos sujeitos - ganham matéria a partir dos múltiplos textos que circulam em uma sociedade. Num território marcado por interdiscursos e seus embates, como o do (Tele)Jornalismo, é constante o esforço para manter uma ilusão de unidade de sentido, por meio de representações. Neste texto, focalizamos a circulação de enunciados com foco privilegiado sobre o noticiário televisivo e delineamos articulações entre práticas discursivas e linguagens midiáticas. Reforçamos, ainda, a importância da aproximação entre os campos da Análise do Discurso e os estudos de jornalismo em TV, tendo no telejornalismo local a aplicação da $\mathrm{AD}$ para compreensão do papel dos discursos na re-produção das identidades sociais.

Palavras-chave: Telejornalismo; análise de discurso; representação; sentido; identidade local.

\section{Meanings and subjects on scene in TV news: The incorporation of discourse analysis in TV news studies}

\begin{abstract}
Senses - and the effects they produce on individuals - consolidate themselves in the texts that circulate in society. In a field characterized by interdiscurses and their shocks, like (TV) Journalism, the effort to keep an illusion of sense unity, by means of representations. In this text we focus on the circulation of statements, specially the TV newscast and make some articulations between discursive practices and midiatic languages. We emphasize the importance of approaching the fields of Discourse Analysis and Journalism studies, having in the local TV newscast the place to apply $\mathrm{AD}$ and comprehension of the role played by discourses in the re-production of social identities.
\end{abstract}

Keywords: TV newscast; discourse analysis; representation; sense; local identity. 


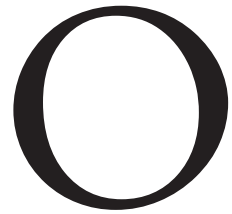

s sentidos - e os efeitos que estes produzem nos sujeitos - ganham matéria a partir dos múltiplos textos que circulam em uma sociedade. Num território marcado por interdiscursos e seus embates, como o do (Tele)Jornalismo, é constante o esforço para manter uma ilusão de unidade de sentido, por meio de representações. Neste texto, focalizamos a circulação de enunciados com foco privilegiado sobre o noticiário televisivo e delineamos articulações entre práticas discursivas e linguagens midiáticas. O trabalho reforça a importância da aproximação entre os campos da Análise do Discurso e os estudos de jornalismo em TV, tendo no telejornalismo de produção local em Juiz de Fora um exemplo de aplicação da AD como estratégia para melhor compreensão do papel dos discursos na re-produção das identidades sociais. Antes disso é necessário refletir sobre a produção e circulação de enunciados como um campo de negociações, também simbólicas.

Um sujeito, ao falar de si mesmo e do mundo, disputa poder, controla espaço (s), tenta monopolizar a força referencial e a "verdade" daquilo que (a) enuncia. Para Michel Foucault, a aparição e mesmo a negação do direito de fala são procedimentos existentes nas sociedades- no caso de suas análises a ocidental- para controlar discursos. Em um dos tópicos mais discutidos de sua obra "A Ordem do Discurso", o autor aponta, em severa crítica ao discurso verdadeiro, que ainda na Grécia do século VI, tal discurso era pronunciado por quem de direito e conforme o ritual requerido. Diante deste, todos os demais discursos precisavam submeter-se.

Essa luta por uma "verdade", ainda que discursiva, sofre deslocamentos e passeia pelos séculos, indo da filosofia grega à ciência na idade moderna. E segue adiante, imprimindo "uma espécie de pressão e como que um poder de coerção” (FOUCAULT, 2007, p.18) na literatura, no cinema e no telejornalismo atuais.

A título de rápida exemplificação, temos na literatura a proliferação das publicações definidas como "autoajuda", produzidas, na concepção de Maria do Rosário Gregolin (2007, p.21) como “drogas” para suportar o mal-estar discursivo contemporâneo, proveniente da tensão entre uma desestabilização acelerada e a persistência da referência identitária.

No cinema, pululam discursos de valorização do real, através de documentários e películas baseadas em histórias reais ${ }^{2}$. Fato que não chega a ser recente, tendo-se em vista que a história inicial do cinema se confunde com a própria vontade de trazer para a tela a "realidade crua". Interessante é notar que, mesmo com a tomada de consciência da existência de técnicas na produção de filmes, com a incorporação de diferentes linguagens e gêneros, ainda permanece vigorosa esta vontade de verdade, na busca pela identificação com vidas e histórias tão palpáveis quanto as nossas.

\footnotetext{
${ }^{\top}$ No Brasil, a publicação de obras do gênero teve um crescimento de mais de $700 \%$ nos últimos oito anos, contra um aumento de 35\% do mercado de livros como um todo. Os títulos "A Lei da Atração", de Michael Loster, "Por que os Homens Fazem Sexo e as Mulheres Fazem Amor?", de Allan Pease e "Quem Mexeu no meu Queijo?", de Spencer Johnson, estão na lista dos mais vendidos no país.

${ }^{2}$ O documentário Edifício Master (Videofilmes, 2002), e os filmes baseados em fatos reais: Última parada 174, (Paramount, 2008) de Bruno Barreto - que aborda as últimas horas da vida de Sandro do Nascimento, 22 anos, o "sequestrador do ônibus 174", além de Jean Charles (Imagem Filmes 2009), dirigido por Henrique Goldman são exemplos.
} 
Convém lembrar também da dimensão um tanto "mítica" conferida ao diretor $^{3}$ do filme, que por meio de suas técnicas e escolhas discursivas cria sua marca - rótulo, que, por sua vez, gera expectativas discursivas nos espectadores. A relação entre o discurso e seu autor é vista por Foucault com cautela. Sem negar a existência do criador do discurso, o pesquisador atenta para o fato de que o discurso é, constantemente, atravessado por outros. Assim sendo, deve-se limitar o discurso ao que ele carrega em si do perfil de seu ator.

Embora os questionamentos de Foucault e de outros estudiosos que trabalham ou influenciam a análise de discurso, com Bakhtin e Lacan, não se concentrem especificamente nos elementos midiáticos, a riqueza filosófica que produziram, além da abrangência temática são perfeitamente aplicáveis a diversas áreas de conhecimento. Conforme perceberemos adiante, os estudos de comunicação são exemplo dessa aplicabilidade multifacetada da AD. Numa problematização permanente e atual da temática, o discurso torna-se, na comunicação, lugar de enfrentamentos teórico-metodológicos. Lugar onde verdade e mentira são cada vez mais observadas como uma invenção historicamente constituída.

Desse modo, pretende-se apresentar aqui a pertinência da análise do discurso, sobretudo da teoria foucaultiana, para se pensar a comunicação e focalizar efeitos identitários construídos num complexo emaranhado de discursos, memórias e narrativas. Inicialmente esboçamos as principais características da $\mathrm{AD}$ e de sua relação com a esfera midiática. Em seguida, finalizamos este trabalho apresentando um estudo discursivo de matéria exibida pelo telejornalismo local diário de Juiz de Fora. Interessa-nos apontar a importância da AD para a compreensão dos múltiplos textos e trajetos de sentidos da "linguagem" telejornalística e a função desta na produção social das lutas pelas construções e re-produções de identidades.

\section{Análise do discurso: Uma tendência linguística de meia idade}

Nascida na década de sessenta, num momento discursivamente visto até hoje como a década de choques entre o "antigo" e o "moderno" ou os "anos rebeldes" como muitos preferem estereotipar, a análise do discurso não nega as origens. A Análise do Discurso surge a partir da necessidade de se encarar a linguagem para além de seu papel enquanto instrumento de comunicação ou suporte de pensamento. Ao atentar também para a questão de sua materialidade, a linguagem-discurso se ampara na interação, é um modo de produção social anti-neutralidade, anti-naturalidade, lugar privilegiado para o conflito, para os confrontos ideológicos.

Antes disso, observamos as postulações teóricas de Saussure, com seu conhecido trabalho linguístico no estabelecimento da dicotomia língua/fala e a valorização da primeira sobre a segunda. $\mathrm{Na}$ contramão desta exclusão da fala

\footnotetext{
${ }^{3}$ Temos diversas assinaturas discursivas, como as de Fernando Meireles e sua edição acelerada e que privilegia panorâmicas, Quentin Tarantino e a influência da cultura pop, Pedro Almodóvar e suas cores berrantes, figurinos extravagantes, personagens caricatos, situações delirantes e exageradas.
} 
do campo linguístico, temos as análises de Bakhtin e sua "teoria do enunciado", na qual vê a língua como algo concreto e fruto da manifestação individual de cada falante. À enunciação caberia, neste momento, um lugar privilegiado de elemento "vivo" e real da linguagem. A interação verbal ganha respaldo como elemento fundamental da língua - que, de sistema sincrônico abstrato passa a ser compreendida como signo dialético, dinâmico.

A importância do discurso surge a partir do momento em que se percebe o caráter complexo da linguagem excedendo a oposição língua-fala. Interessa, assim, outra dualidade da linguagem, que abarca seu caráter simultaneamente formal e subjetivo- o discurso- intimamente relacionado às condições sóciohistóricas em que se estabelece. Nas palavras de Helena Brandão:

Se processo discursivo é produção de sentido, discurso passa a ser o espaço em que emergem as significações. E, aqui, o lugar específico da constituição dos sentidos é a formação discursiva. Noção que, juntamente com a de condição de produção e formação ideológica, vai constituir uma tríade básica nas formulações teóricas da análise do discurso. (BRANDÃO, 1998, p.35)

A constituição da análise do discurso enquanto disciplina tem nos trabalhos de Harris (Discourse Analysis, 1952) e de R. Jakobson e E. Benveniste, no campo da enunciação seu momento decisivo de constituição. Os estudos desses autores definirão, nessa ordem, as especificidades teóricas do que posteriormente foram denominadas linhas americana e europeia de análise do discurso.

Eni Orlandi apresenta na obra "Análise do Discurso: princípios e procedimentos" (1986) as nuances que distinguirão estas duas maneiras diferentes de se pensar o discurso. A vertente americana vislumbra na teoria do discurso uma espécie de ramificação da Linguística, "vendo o texto de uma forma mais redutora, não se preocupando com as formas de instituição do sentido, mas com as formas de organização dos elementos que o constituem" (ORLANDI apud BRANDÃO, 1998, p.16).

A perspectiva europeia, por sua vez, vê na crise interna da própria Linguística a necessidade de se caracterizar o discurso como elemento de ruptura, como aquilo que vai além do linguístico. Reforçam-se, com essa tendência, as relações entre o dizer e as condições de produção desse dizer. Extrapolam-se os limites da Linguística na tentativa de dar conta de uma análise não imanente, conflituosa, exterior e complexa da linguagem.

Neste contexto, a escola francesa de análise do discurso (AD), priorizada em nosso trabalho, surge nos anos 60 com o objetivo de enfocar o discurso em âmbito interdisciplinar. Importa, na definição do discurso, o quadro de instituições em que é produzido e os embates histórico-sociais travados para sua cristalização. Articulando o linguístico com o social, a AD busca, num cenário estruturalista, recursos para "explicação do texto" em outras áreas de 
conhecimento, bem como auxílio do marxismo e da psicanálise. Inicialmente servindo de base ao estudo de discursos políticos, a $\mathrm{AD}$ se rende à polissemia e passa a ser utilizada em diversos campos de atuação, como acontece até hoje. Atual, aliás, como a utilização dos conceitos de discurso e ideologia, derivados, respectivamente, de Foucault e Althusser e emprestados por Pêcheux em seus trabalhos na escola francesa.

Concebendo todo discurso como uma dispersão, Foucault vê na análise do discurso um conjunto de aparatos que fornece "regras de formação" capazes de descrever e regularizar essa carência de unidade: objetos discursivos, tipos de enunciação, conceitos, temas e teorias. Cabe ressaltar que a noção de enunciado em Foucault é contraposta à noção isoladora de frase, tendo como característica extremamente importante para a $\mathrm{AD}$ a relação enunciado-sujeito. Interpretado aqui como instância não fundadora da linguagem, o sujeito dispõe de signos, marcas e textos mas não origina o objeto pensado. A análise desloca-se das relações entre o autor e o que ele diz para a posição que este indivíduo ocupa (dentre várias possíveis no discurso) para ser sujeito, tomado como um espaço a ser preenchido. Nos são caros, ainda em Foucault, a ideia de jogo enunciativo, onde há encadeamento de enunciados que se interpenetram e fogem da neutralidade e a distinção entre enunciação e enunciado.A primeira só depende da emissão de signos, enquanto o segundo jamais se repete, dependerá sempre do contexto de sua localização.

Ao perceber o discurso como algo adiante do aspecto linguístico Foucault relaciona o "discurso verdadeiro" como elemento estratégico de dominação/ esquiva utilizado institucionalmente para gerar poder e conter forças opostas ao mesmo.

A ideologia também é percebida, sob outro viés, como elemento de dominação. Se para Marx a ideologia (num cenário de crítica ao capitalismo) abarca as ideias da classe dominante, que regula a produção e distribuição de ideias de seu tempo, e faz com que suas ideias passem a ser de todos, em Althusser, apesar desta influência, o conceito terá suas peculiaridades. A começar pelo descentramento dos mecanismos de perpetuação das ideologias. Em Marx, eles dependem da classe dominante e sua função de "mascaramento" e distorção da realidade social. Já para Althusser terão tônus no papel do Estado e seus aparelhos opressores, como Governo e polícia e aparelhos ideológicos, como religião, escola, família, cultura, dentre outros. Estes últimos atuariam no sentido de, mesmo que dissimuladamente, re-produzir (e não apenas escamotear) condições de produção e demarcar, por meio da ideologia, posições de classe.

A existência da ideologia, embora numa relação imaginária, passa a ser encarada como material, visto que "as relações vividas, nela representadas, envolvem a participação individual em determinadas práticas e rituais no interior de aparelhos ideológicos concretos" (BRANDÃO, 1998, p.23). Assim, numa oposição ao conceito de ideologia como simples mimese da realidade, o homem produz representações para se relacionar com a realidade. A ideologia passa a ser entendida como algo inerente ao signo, permitindo produzir sentidos novos, minimizar outros e limar sentidos incômodos.

Michel Pêcheux é tributário de algumas conceituações de Althusser, sobre- 
tudo na defesa da "existência material" das ideologias. Com influências também da noção de formação discursiva foucaltiana, de Bakhtin e o fundamento dialógico da linguagem, além de Lacan e as temáticas do inconsciente derivadas de Freud, os estudos de Pêcheux norteiam diversas pesquisas em análise do discurso realizadas hoje no Brasil.

Ressalte-se que, apesar de múltiplos diálogos, o "discurso" de Pêcheux não é o mesmo de Foucault. E se pensarmos na tradição anglófone a distância aumenta, porque o discurso de Norman Fairclough ${ }^{4}$ também não se aproxima das questões francesas. O que temos são vias, diferentes possibilidades de compreensão de um problema posto diferentemente por cada autor. O que significa que não há uma "teoria" mais aceita atualmente, mas sim caminhos teóricos que respondem e co-respondem em parte às necessidades de reflexão que se apresentam.Todas as contribuições citadas atuarão num campo onde se cruzam língua, sujeito e história na tentativa de abordagem da heterogeneidade que compõe o discurso. Vem de Pêcheux a elaboração de Formação Discursiva (FD) concebida por Foucault, lugar privilegiado de articulação entre língua e discurso na AD. Luta ideológica fluída e instável a FD permite, de acordo com Brandão

Dar conta do fato de que sujeitos falantes, situados numa determinada conjuntura histórica, possam concordar ou não sobre o sentido a dar às palavras, 'falar diferentemente falando a mesma língua'.Isso leva a constatar que uma FD não é 'uma única linguagem para todos' ou 'para cada um sua linguagem', mas numa FD o que se tem é 'várias linguagens em uma única”(BRANDÃO, 1998, p.39).

Quer seja na versão marxista, onde a utilizamos sem todavia trazê-la aos níveis da consciência, quer produzida intencionalmente, como na publicidade, o papel da ideologia, aliada à análise do discurso e à formação discursiva, tornam-se concepções nucleares para o campo da Comunicação como um todo e em nossos estudos de Comunicação e Identidades.

\section{Jornalismo e análise do discurso: um diálogo permanente}

Ao estabelecer um quadro onde lista os Modelos Teóricos para o Estudo das Comunicações, Venício Lima (2001, p.46) situa a Análise do Discurso no subgrupo "Linguagem", juntamente com a semiologia e a semiótica. O

\footnotetext{
${ }^{4}$ Os livros de Norman Fairclough Language and Power (1989) e Critical Discourse Analysis (1995) articulam um quadro tridimensional para o estudo do discurso, "onde o propósito é mapear três formas separadas de análise em uma só: análise de textos (falados ou escritos), análise da prática discursiva (processos de produção, distribuição e consumo dos textos) e análise dos eventos discursivos como instâncias da prática sociocultural" (1995, p.2). Fairclough é um dos maiores nomes da chamada Análise Crítica do Discurso (ACD). Esta instaura uma abordagem interdisciplinar ao estudo dos textos, considerando a "linguagem como uma forma de prática social" (Fairclough 1989, p.20) e pretende desvelar os fundamentos ideológicos do discurso - que se têm feito tão naturais ao longo do tempo que começamos a tratá-los como comuns, aceitáveis e traços naturais do discurso. Para maior detalhamento da ACD consultar as obras supracitadas do autor.
} 
autor explica que, no Brasil, esses estudos marcados pela proposta teórica do estruturalismo semiótico-linguístico de origem europeia, vêm ganhando força a partir dos anos 70. A bibliografia utilizada, segundo Lima, muitas vezes se confunde com a de cursos como teoria literária, letras e linguística, origem de muitos programas de pós-graduação em comunicação. A discussão central em torno do "sentido", das múltiplas leituras possibilitadas por uma mesma mensagem, até então ausentes das teorias das comunicações justificam a pertinência destas propostas.

A atual convergência de pesquisas e de questionamentos metodológicos configura-se, nas observações de Giovandro Marcus Ferreira (2003, p.267), como algo recente. Vendo a análise do discurso sob um viés histórico, o autor evidencia a $\mathrm{AD}$ como um domínio de estudos onde o encontro de disciplinas atual contrasta com uma "ilha de isolamento" no passado. Ilhada inclusive da Sociologia e seu tradicional diálogo com o campo da comunicação e fadada à investigação do intra-textual, a análise do discurso "antropologiza-se" em contato com os estudos culturais e ganha força com a incidência das pesquisas de estudiosos como Dominique Maingueneau e Eliseo Veron, principalmente a partir da década de 90 .

A relação cultura-meios de comunicação faz com que, tanto a sociologia quanto os estudos de discurso migrem, em boa parte, para a análise da recepção, destacando a relação contratual dos MCM com seu público. Essa fase de abertura é vista, por algumas abordagens, como a terceira fase da semiologia, onde se prioriza a polêmica e complexa relação texto-contexto e as diferentes modalidades de enunciação. Crucial apreender desta fase o estabelecimento da noção de "contrato discursivo", que sugere o engajamento (ou não) de determinado público com os meios de comunicação, viabilizado por estratégias discursivas. Termo que ainda hoje gera polêmicas e redefinições que tentam tornar esse "entrosamento" algo menos normativo, como a de "promessas discursivas".

Campo solidamente em atividade no Brasil, a AD toma cada vez mais a mídia como objeto de investigação. O panorama inclui propostas complementares, que têm na produção social de sentidos a sua riqueza. Para Maria do Rosário Gregolin (2007, p14), o que caracteriza essas abordagens é, "principalmente, o fato de os pesquisadores colocarem-se como tarefa a problematização permanente das suas bases epistemológicas", encarando o discurso como lugar de enfrentamento de teorias e de metodologias.

A ideia de "agenciamento discursivo", que tenta, por meio do controle e distribuição do discurso criar uma ilusão de "unidade do sentido", torna-se algo evidente na mídia, inclusive por parte da recepção. Diferentes recortes de realidade são ofertados ao leitor/espectador/telespectador/consumidor dos produtos midiáticos. Mediação que permite a produção de formas simbólicas de representação do indivíduo com sua "realidade concreta". Representações e narrativas dotadas de "materialidade repetível" (FOUCAULT, 2004, p.121122) e que oferecem uma "história do presente" dia após dia, por meio de textos verbais e não-verbais de jornais, revistas, internet e, no caso do Brasil, principalmente pela TV.

Por meio de ressignificação de imagens e palavras enraizadas no passado, rememoramos e esquecemos símbolos e representações, num constante mo- 
vimento interpretativo e de sentidos. O que são as comunidades, as nações, senão discursos que transcendem territórios e etnias e dependem cada vez mais do espaço de convivência e da narrativa compartilhada possibilitados pelos MCM? O que é ser brasileiro para além do samba no pé, do jeitinho, do futebol? A porção de brasileiros que constituem seu discurso de brasilidade sem "travar contato" com a mídia, beira o zero estatístico, tendo-se em vista que $97 \%$ da população tem acesso a algum meio de comunicação.

Nesta ótica em que os sujeitos são sociais e os sentidos são históricos, os discursos lançam-se em verdadeiras batalhas encabeçadas pela "vontade de verdade". Foucault (1978) vê nesta movimentação uma "microfísica do poder". Basicamente, temos no campo social uma contínua luta pelo estabelecimento de verdades, que, por dependerem da história, sofrem da instabilidade e da "permanente necessidade de modificação". Conceitos como verdade, neutralidade discursiva e objetividade tornam-se relatividades estabelecidas pelos jogos desses micropoderes, também no campo da comunicação.

É o que perceberemos em seguida, no nosso recorte sobre o telejornalismo local. Cumpre-nos mostrar, nesse tipo de produção, a importância da Análise do(s) discurso(s) para compreendermos a circulação e profusão de textos e imagens atuando como dispositivo de rotulagem e disciplinamento do corpo social - no caso a audiência do Telejornal da Alterosa, Edição Regional.

\section{Telejornalismo e análise do discurso: Produção e disputas de sentido por meio de ausências e presenças do povo no noticiário local}

No decorrer da obra "Ideologia e aparelhos ideológicos do Estado (ALTHUSSER,1970 apud BRANDÃO, 1998), Althusser assinala que a diferença entre os aparelhos repressores e os aparelhos institucionais estaria em sua forma de ação. No primeiro caso temos a atuação da repressão, inclusive física prevalecendo sobre a força da ideologia. Já nas instituições, o inverso se sucede. A hegemonia ideológica figura como algo imprescindível para reproduzir as relações de produção.

No caso do telejornalismo local de Juiz de Fora, "produto" que oferece recorte empírico para esta reflexão, a criação e manutenção de vínculos com a comunidade/audiência constitui-se em desafio cotidiano para os jornalistas. $\mathrm{E}$ tem na força discursiva da representação do "universo do popular"- viabilizada por entrevistas de populares e utilização de recursos como "povo fala", sua principal estratégia de aproximação com o público. Vale reforçar que o produto oferecido aos telespectadores é uma (re) construção da realidade, operada via coleta de imagens, redação de texto, edição, ângulos de enunciados, cuja "vontade de verdade" é garantida muitas vezes pela soma de tentativas de repetição de alguns fatos, amarrados pelos textos de repórteres e apresentadores, numa imitação da ação humana.

Considerando a atual força do telejornalismo e seu papel institucional na 
disseminação de lutas simbólicas, destacamos para análise a matéria que abre a edição do Telejornal da Alterosa Regional ${ }^{5}$, no dia 20/05/09. A produção aborda uma (ainda) provável paralisação dos rodoviários, no caso motoristas e outros funcionários de ônibus coletivos de Juiz de Fora. Exemplar, a matéria nos faz pensar sobre a função do discurso da mídia na produção de identidades. Neste recorte, é possível "experimentar com olhos e ouvidos" o jogo polissêmico utilizado na representação do povo na $\mathrm{TV}^{6}$.

A começar pelo texto da matéria na escalada do telejornal. Nele, a âncora anuncia que "O Jornal da Alterosa mostra hoje o perigo das paralisações. Educação, saúde e até os rodoviários ameaçam cruzar os braços”. A rememoração da expressão "cruzar os braços", de pronto, tenta fixar-se no passado e estabelecer com o telespectador um rápido jogo de "flashback imagético", onde, dentre muitas outras conceituações possíveis, temos a tradicional cruzada de braços símbolo de rebeldia. $\mathrm{O}$ mesmo gesto lançado contra a exploração de trabalhadores da indústria, num contexto de pós- guerra ou feito por metalúrgicos do $\mathrm{ABC}$ Paulista contra patrões, o "sistema", as más condições de trabalho. Ou ainda, o entrelaçar de braços de atrizes reivindicando, na década de 80 , o reconhecimento da profissão e o fim da censura.

A memória da narrativa tradicional, sob a forma de "materialidade repetível" (Foucault, 2004, p. 121) transportada para o acontecimento jornalístico e aliada à expressão perigo tenta produzir, na audiência, medo e apreensão. Nesta transfiguração temos o cruzamento de sentidos imemoriais de resistência, repreensão e violência, produzindo entrelugares nos quais as identidades travam uma "incômoda batalha". Sem falarmos do encadeamento de enunciados - a possível falta de educação, saúde e transporte, que, no papel de elementos fundamentais para o bom "funcionamento" (e por que não dizer controle) do corpus urbano cumprem o papel de reforço do medo nesta narrativa do noticiário. O efeito é potencializado na cabeça da matéria, onde a apresentadora reforça que "Professores municipais, médicos de braços cruzados e para piorar ainda mais a situação surge agora a possibilidade de uma outra paralisação: dos profissionais dos transportes coletivos". Por abordar um fato que ainda não aconteceu , as imagens de arquivo de uma greve do gênero ocorrida há dois meses atuam no sentido de oferecer ao público a contextualização pretendida.

Teun van Dijk , ao relacionar discurso com situações e estruturas sociais, denomina modelo de situação na memória, a representação que o leitor guarda de experiências e informação sobre uma determinada situação. De maneira cognitiva, a "leitura" de uma notícia, no caso do telejornal ou de qualquer outro meio, leva à construção de um modelo particular da situação ou do evento tratado no texto, por meio da atualização dos modelos mais gerais.

\footnotetext{
${ }^{5}$ Em Juiz de Fora, as possibilidades de a população local "se ver na TV" resumem-se, basicamente, a dois noticiários televisivos: O MGTV- telejornal com duas edições diárias da emissora Panorama, afiliada da Rede Globo e o Jornal da Alterosa, no ar desde 2000. O telejornal diário, voltado para as classes C, D e E na concepção da editora, integra a grade de programação da TV-Alterosa, afiliada à Alterosa de Belo Horizonte que, por sua vez, pertence ao SBT.

${ }^{6}$ Os frames capturados e aqui presentes explicitam a (ainda) impossibilidade de demonstrarmos em multimídia a multiplicidade de discursos que permeiam a matéria. Entretanto, acreditamos que nossos "recortes de recortes" possam contribuir para ilustrar nossa análise e deixá-la menos exposta à ação descritiva da notícia, o que contradiz, inclusive a perspectiva da AD.
} 
Em virtude do próprio tempo neste tipo de produção, relativamente curto, a contextualização torna-se grande desafio para o profissional de comunicação. Isto evidencia o papel do leitor na compreensão daquilo que é relatado. Ele "não recebe os pormenores através da estrutura da notícia, por razões diversas. Irá reconstruí-los através de seus conhecimentos adquiridos anteriormente". (VAN DIJK apud JENSEN, K. B. e JANKOUSKI, N.W, 1993, p.146).

$\mathrm{Na}$ tentativa de facilitar essa atualização, as imagens de arquivo são resgatadas do passado, pelo enunciado da âncora, coberto por imagens "antigas" da multidão na rua e de avenidas sem ônibus. Elas tentam, ainda, se estabelecer como uma narrativa do presente e de uma futura repetição do passado, quando a apresentadora anuncia que: "No dia nove de março deste ano Juiz de Fora parou. A greve dos rodoviários atrapalhou muita gente que precisava trabalhar, estudar, enfim, que precisava do transporte coletivo. Relembre com Evandro Medeiros e Michele Pacheco". A partir daqui, o crédito "arquivo" que aparece na tela ao lado de repórteres e entrevistados não impede a ação da vontade de verdade e nem mesmo que a recepção possa contextualizar a situação e re-atualizar as angústias sofridas há dois meses. Dessa forma, como é possível em todo processo discursivo, o emissor pode antecipar as representações do receptor e, de acordo com essa antevisão do "imaginário" do outro, fundar estratégias de discurso.

A primeira matéria de arquivo inserida nesta "macromatéria retrospectiva" traz a repórter, à noite, em frente à garagem de uma das maiores empresas de ônibus de Juiz de Fora. Diversos recursos nos dão pistas de uma aproximação entre o discurso do telejornal com a tensão típica de thrillers policiais, que envolvem a privação de liberdade e negociações: a baixa iluminação (fig.1), a tensão na voz da repórter, ao proferir seu texto, ressaltando que "A situação foi tensa durante toda a madrugada. A polícia militar ficou a postos para evitar tumultos (...) do lado de dentro ficaram alguns representantes do sindicato negociando a saída de alguns carros. Por enquanto, até às quatro da manhã ninguém pode sair”. Surge a imagem e declarações de funcionários contrários à greve em posição de rivalidade com o sindicato, que queriam trabalhar e estavam "revoltados", de acordo com a adjetivação da repórter. Eles queimam, no local, uma faixa colocada pelo sindicato dos rodoviários na porta da empresa, com os (controversos) dizeres: "Trabalhadores do transporte coletivo em greve.Unidos venceremos". (figs. 2 e 3 )

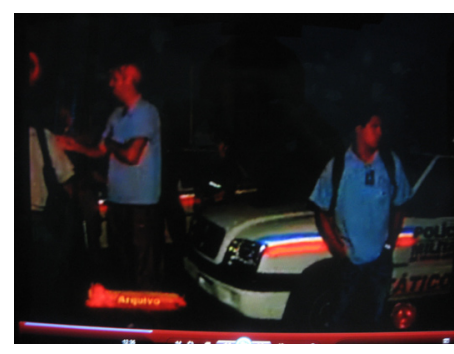

Figura 1

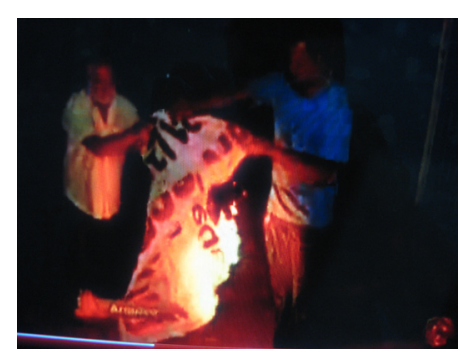

Figura 2

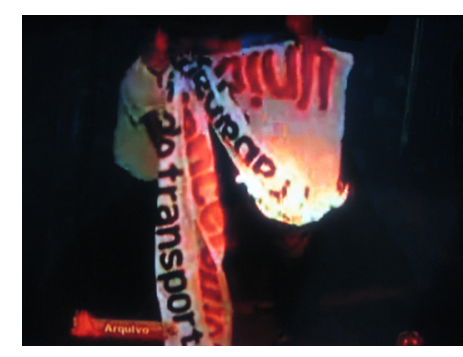

Figura 3

Emblemática, a imagem cumpre um trabalho discursivo tradicionalmente desempenhado pelos mitos- a reprodução de imagens culturais. O processo é assegurado pela ampla oferta de modelos difundidos e impostos socialmente pela imitação e formas ritualizadas, relatividades estabelecidas pelos jogos dos 
micropoderes citados por Foucault. No exemplo, o movimento de interpretação/reinterpretação da mensagem midiática remete ao poderio simbólico do elemento fogo e de sua associação a uma matriz que abriga sentidos imemoriais de violência, insurreição, de situação-limite. É, grosso modo, dentre inúmeras outras possibilidades imagéticas, o mesmo fogo com que Nero incendeia Roma, que consome na fogueira Joana D'arc. Ou até as labaredas estereotípicas que ora destroem e noutras vezes dão conta do "design"- espécie de papel de parede- do inferno cristão. Tais pacotes de identidades são, na concepção de Gregolin socialmente úteis, pois estabelecem paradigmas, maneiras de agir e pensar que, simbolicamente, inserem o sujeito na "comunidade imaginada". A pesquisadora completa que

a sofisticação técnica produz uma verdadeira saturação identitária pela circulação incessante de imagens que têm o objetivo de generalizar modelos. A profusão dessas imagens age como um dispositivo de etiquetagem e de disciplinamento do corpo social (GREGOLIN, 2OO7, p. 17)

Num contexto semelhante de agenciamento de enunciados, a matéria de arquivo seguinte se inicia com o barulho da sirene de ambulâncias em meio aos ônibus e população no centro da cidade (fig.4) A narrativa imagem/texto casa-se discursivamente com a assinatura simbólica da produção que lhe antecedera. No texto do repórter, representantes do sindicato dos rodoviários, numa operação que remete aos discursos de rotina entre polícia/bandidos, "negociaram com a polícia o fechamento da Avenida Rio Branco" (fig.5). De braços cruzados e organizados em círculo, os rodoviários proferem sua indignação a um policial que se coloca no centro deste círculo - e também no centro do discurso, por seu papel de mantenedora da ordem. Um manifestante declara, ao policial e, portanto, indiretamente à lente da câmera que "Se eles devolverem o nosso tíquete que eles retiraram, a gente volta a negociar. Aí suspende a greve, também não acaba não"(fig 6).

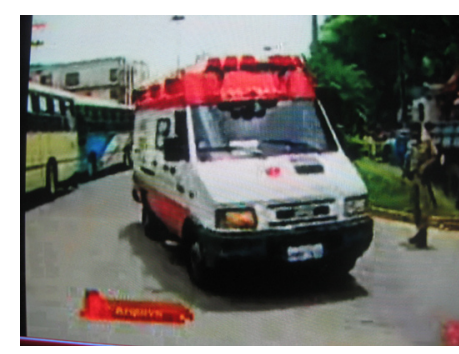

Figura 4

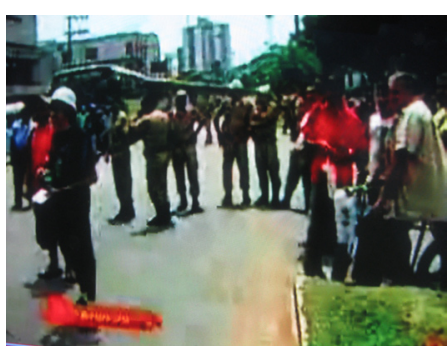

Figura 5

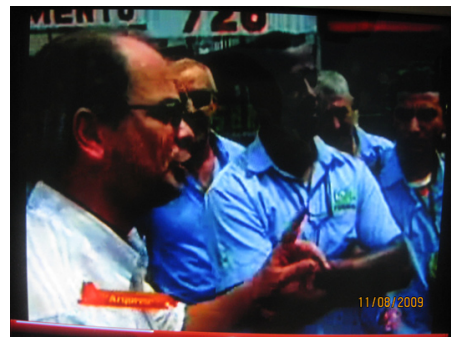

Figura 6

Temos, em sequência, um dos mais importantes pontos de interesse da análise da participação popular nesta matéria. O repórter, em off que cobre as imagens de uma mulher/ cidadã/ passageira, em postura de revolta com os rodoviários, adianta que, durante a manifestação "Ouve bate boca. Alguns passageiros se revoltaram”. A mulher, com traços típicos de nervosismo, aponta o indicador para um dos representantes do sindicato e brada "Vai atravessar um filho seu". O nervosismo da passageira, com a voz alterada se contrapõe à calma do rodoviário, que toma um sorvete enquanto tem o indicador da senhora apontado para seu rosto. (figs. 78 e 9). 


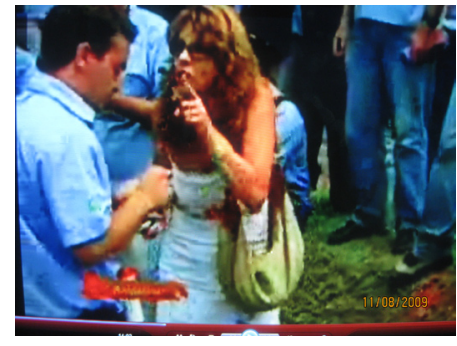

Figura 7

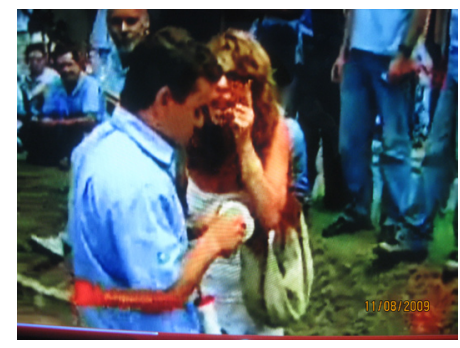

Figura 8

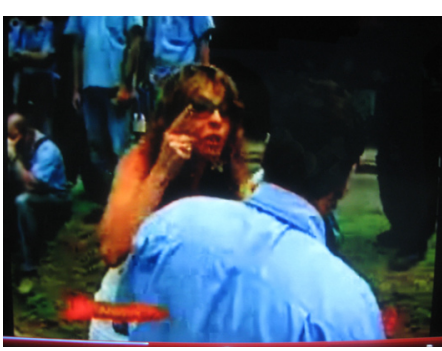

Figura 9

A ideia de povo como multidão que precisa de controle, de constante vigilância por parte dos Aparelhos Repressores (AR) - nesta situação a políciaganha forma e atinge seu ápice. $O$ agenciamento coletivo desta enunciação se solidifica às custas da postura agressiva da mulher sem nome. Descreditada tanto literalmente, pela ausência de identificação na tela, quanto discursivamente, pela própria desqualificação de seu exercício de cidadania e de suas palavras de indignação, classificadas pelo repórter como mero "bate boca".

Assim, cabe-nos uma comparação com o texto de Foucault em A Ordem do Discurso, quando o autor discorre sobre o ritual, uma das formas de restrição do discurso, de controle do poder. No ritual ocorre a delimitação das "qualidades" de cada indivíduo que fala e que "num jogo de diálogo, da interrogação, da recitação, devem ocupar determinada posição e formular determinado tipo de enunciado" (FOUCAULT, 2007, p.39).

Gestos, comportamentos, circunstâncias e todo um conjunto de signos acompanham o discurso e tentam impor, através da coerção, seu efeito sobre aqueles aos quais se reportam. Tal processo, ao ser transposto para o campo da comunicação traz como ponto de partida da análise a seguinte questão: Como o acontecimento é contado pelo discurso do telejornal? A recitação e a construção simbólica do acontecimento mediático é retomada, por exemplo, na interrogação da apresentadora, ao vivo, em estúdio, interagindo com a repórter via telão. A âncora convida o telespectador para um exercício imaginativo de uma mazela em vias de se tornar realidade e questiona à repórter (fig.10): "Já imaginou essa confusão toda de novo? Não vai ser fácil não". A repórter, por sua vez, informa que, após dois meses, a "trégua"- (aqui temos mais uma palavra com forte potencial simbólico) entre rodoviários e as empresas de ônibus se encontrava em seus momentos finais. A jornalista entrevista o vice-presidente do sindicato (fig.11), que em tom calmo e buscando aproximação/ domínio discursivo com a audiência, frisa que "essa trégua foi feita pelos trabalhadores em consideração ao povo de Juiz de Fora e para demonstrar que o movimento era reivindicatório" e não de defesa de aumento tarifário de passagens. Em um próximo momento, um trabalhador rodoviário aparece oferecendo uma pergunta para o representante do sindicato. Interessante adiantar que o entrevistado, reclamando da postura omissa do sindicato e das más condições de trabalho não é identificado e aparece com voz alterada e luz estourada (fig.12), alegando que trocadores e motoristas trabalham sob "grande pressão" e indagando se é "justo um cobrador ganhar por mês 190 reais de adiantamento e menos de 200 reais por mês no pagamento? E o nosso sindicato, em contrapartida, não diz nada”. A apresentadora repassa a palavra à repórter, por meio da expressão "Taí o desabafo, Michele”. Mais significativa que a mediação feita pelo telejornal entre trabalhadores e representantes do 
sindicato, temos os diferentes "lugares de fala" de cada envolvido delimitando posições discursivas totalmente diferentes.

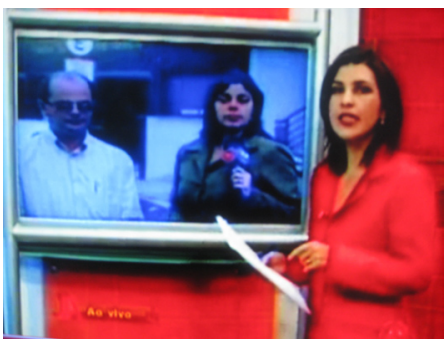

Figura 10

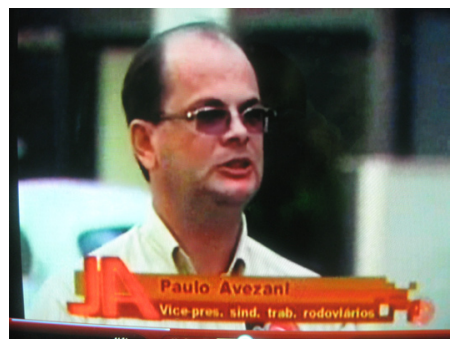

Figura 11

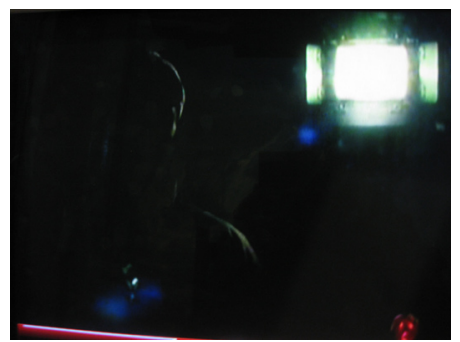

Figura 12

Os primeiros figuram sem identificação, o que não significa sem identidade. Esta pauta-se na submissão enunciativa daqueles que precisam se ocultar para que haja permissão de fala. O que, de início, já os coloca em posição desprivilegiada em relação aos membros do sindicato, que têm direito a um nome e também o próprio direito de resposta, já que "um dos seus" se encontra ao vivo, ao contrário do homem sem nome e sem "feições". Obviamente estamos cientes das retaliações das quais o trocador de ônibus foge, o que não retira da narrativa do telejornal analisado o papel de reforçar/ cristalizar esse discurso de submissão, por um lado e de micropoderes de outro. Como os sujeitos são sociais e os sentidos históricos, há confronto de discursos que expressam as lutas em torno de dispositivos identitários.

Estas lutas não se entrelaçam somente na matéria analisada. Estão presentes, na mesma edição, no conjunto de matérias que compõem outras produções do tipo, que se alicerçam nesta simbologia de apreensão e alerta permanente da sociedade como elemento de identificação. Inclui a abordagem da paralisação de médicos e de professores, além de problemas de moradores de um bairro que, por excesso de terrenos baldios, encontraram uma cobra dentro de casa. E se apresentam ainda ao longo das edições, conforme trabalho anterior onde constatamos a escolha de fontes populares como estratégia para garantir espaço mercadológico e importante ponto de apoio para a constituição profissional dos produtores ${ }^{7}$.

\section{Considerações finais}

A pesquisa aqui apresentada caminha distante da pretensão de apontar, equivocadamente, "falhas discursivas" no telejornal analisado. Seguimos os passos teóricos de Foucault e seu raciocínio de que todo e qualquer discurso é controlado. E de que, assim sendo, não podemos falar em discurso nem enunciador únicos. Cumpre-nos valorizar a sutura que ocorre entre os diversos elementos que compõem a matéria e nos dão a dimensão simbólica que o telejornalismo local possui na composição das identidades, dentre as quais a classe denominada "popular" emerge como elemento "(des) norteador" de nossas anteriores e futuras análises.

\footnotetext{
7 Para maior detalhamento sobre a relação povo/ telejornalismo local, consultar MATA, Jhonatan. A voz do povo é a voz de Deus?Participação popular no telejornalismo local. Trabalho de conclusão de curso para obtenção de grau de Bacharel em Comunicação Social na Faculdade de Comunicação Social da UFJF, Juiz de Fora, 2008.
} 
Nossa relativamente breve discussão de relação $\mathrm{AD} /$ mídia nos parece satisfatória em apontar o valor da Análise do Discurso para a compreensão de sentidos e representações tecidos pelos meios de comunicação de massa. Principalmente se compreendemos que esses agenciamentos de formação discursiva não são passivos e acotovelam-se, constantemente, com discursos de resistência, singularizações e outros pontos fugidios. Trabalhamos, a todo o momento, com enunciados marcadamente institucionalizados, onde à realidade não resta outra opção se não a do recorte, do enfoque, do enquadramento da notícia. E esse "modo de ser do mundo", veiculado por tais discursos é sempre o recorte que determinada instituição faz da realidade, retratando, dessa maneira, ainda que enviesadamente, uma visão de mundo. Visão esta que nos faz, nas palavras de Ricouer,(1988) "tomar a imagem pelo real”. E que, ao mesmo tempo, esbarra na limitação dos contratos comunicativos e no paradoxo de suas finalidades: informar e seduzir seu público, segundo as diversas articulações aqui apresentadas e a partir das imposições e recursos estratégicos que o discurso aglutina.

\section{Referências Bibliográficas}

BRANDÃ O, Helena H. Nagamine. Introdução à análise do discurso. 7 ed. Campinas, SP: Editora da UNICAMP. 1988.

COUTINHO, Iluska. Leitura e Análise da Imagem. In Duarte, Jorge \& Barros, Antônio. Métodos e técnicas de pesquisa em Comunicação. São Paulo: Atlas, 2005.

FERREIRA, Giovandro Marcus. Contribuições da Análise do Discurso ao Estudo de Jornalismo. In FRANÇA, Vera [et al.] (org) Livro do XI Compós 2002:Estudos de comunicação. Porto Alegre : Sulina, 2003.

FOUCAULT, Michel. A ordem do discurso. São Paulo: Edições Loyola, 2007. FOUCAULT, Michel. A Arqueologia do saber. Rio de Janeiro:Forense Universitária, 2004

FOUCAULT, Michel. Microfísica do poder. Trad. Roberto Machado. 14 ed. Rio de Janeiro: Edições Graal, 1978.

GREGOLIN, Maria do Rosário. Análise do discurso e mídia: a reprodução de identidades". In: Comunicação, Mídia e Consumo/ Escola Superior de Propaganda e Marketing. v.4, n. 11 (novembro 2007)- São Paulo: ESPM, 2007.

HARRIS, Z. Discourse analysis. Language, New York, v. 28, n. 1, 1952.

LIMA, Venício A. de. Mídia: teoria e política. São Paulo: Editora Fundação Perseu Abramo, 2001.

RICOEUR, Paul. Interpretação e ideologias. 3ed. Rio de Janeiro: F. Alves, 1988.

TUPIASSU, Lúcia Ferreira. Os múltiplos discursos de Edifício Máster. In: XIV Congresso de Ciências da Comunicação na Região Sudeste, Rio de Janeiro. Anais, Rio de Janeiro, 2009. CD-ROM.

VAN DIJK, Teun. "El estúdio interdisciplinario de las noticias y el discurso", in JENSEN, K.B. e JANKOUSKI, N.W. Metodologias qualitativas de investigación em comunicación de masa. Barcelona, 1993. 